\title{
Prostate stem cell antigen rs2294008 polymorphism differentially contributes to Helicobacter pylori-negative gastric cancer among various populations in China
}

\author{
JIUDA ZHAO ${ }^{1,2}$, PAILI GENG ${ }^{2}$, ZHANQUAN LI $^{3}$, SEN CUI $^{3}$, JUNHUI ZHAO $^{1}$, LIJUAN WANG $^{1}$, \\ JINZHANG LI ${ }^{1}$, FAXIANG JI ${ }^{1}$, GUOYUAN LI ${ }^{1}$, GUOSHUANG SHEN ${ }^{1}$, \\ MINGZHE LIN ${ }^{1}$ and CUNFANG SHEN ${ }^{2}$
}

\begin{abstract}
${ }^{1}$ Department of Internal Medicine-Oncology, Affiliated Hospital of Qinghai University; ${ }^{2}$ High Altitude Medical Research Center, Qinghai University; ${ }^{3}$ Department of Hematology, Affiliated Hospital of Qinghai University, Xining, Qinghai 810000, P.R. China
\end{abstract}

Received October 21, 2012; Accepted January 8, 2013

DOI: $10.3892 / \mathrm{mco} .2013 .70$

\begin{abstract}
Gastric cancer is a lethal disease with a high mortality rate. Studies have suggested that prostate stem cell antigen (PSCA) rs2294008 polymorphism is associated with gastric cancer (GC). In this case-control study, we investigated rs2294008 polymorphism in the Tibet, Hui and Han nationalities in the Qinghai area of China. Genomic DNA was extracted from the peripheral blood of 286, 315 and 350 healthy volunteers and from 219, 233 and 265 Helicobacter pylori-negative non-cardia GC patients from the Tibet, Hui and Han populations, respectively. The rs 2294008 polymorphism was analyzed by denaturing high-performance liquid chromatography. rs2294008 CT and TT genotypes were associated with GC both in the Tibet and Han populations (adjusted $\mathrm{OR}=1.51,1.47$, 2.01, 1.85; 95\% CI, 1.04-2.19, 1.05-2.06, 1.04-3.88, 1.03-3.34; $\mathrm{P}=0.030,0.025,0.039,0.040$, respectively). rs 2294008 TT genotype was associated with $\mathrm{GC}$ in the Hui population (adjusted OR=2.14; 95\% CI, 1.29-3.55; $\mathrm{P}=0.003$ ). Furthermore, when stratified by histopathology, the rs $2294008 \mathrm{CT}$ and TT genotypes were associated with diffuse GC in the Tibet and Han nationalities (adjusted OR=1.93, 1.73, 2.69, 2.86; 95\% CI, $1.09-3.44,1.01-2.95,1.06-6.84,1.27-6.46 ; \mathrm{P}=0.025,0.045$, $0.038,0.011$, respectively). However, the rs2294008 TT genotype was associated with both intestinal and diffuse types of GC (adjusted OR=2.10, 2.21; 95\% CI, 1.17-3.75, 1.12-4.38; $\mathrm{P}=0.012,0.023$, respectively) and the rs $2294008 \mathrm{CT}$ genotype was only associated with intestinal-type GC in the Hui nationalitiy group (adjusted $\mathrm{OR}=1.60 ; 95 \% \mathrm{CI}, 1.04-2.47 ; \mathrm{P}=0.034$ ). The results therefore showed that rs2294008 may differentially contribute to GC among different nationalities in one area and its role is independent from Helicobacter pylori-infection.
\end{abstract}

Correspondence to: Dr Jiuda Zhao, Department of Internal Medicine-Oncology, Affiliated Hospital, Qinghai University, 29 Tongren Avenue, Xining, Qinhai 810000, P.R. China E-mail: jiudazhao@126.com

Key words: gastric cancer, prostate stem cell antigen, polymorphism

\section{Introduction}

Gastric cancer (GC) is estimated to be the fourth most common cancer and the second leading cause of cancer-related death worldwide, with $\sim 40 \%$ GC cases occurring in China (1). The mortality of GC in China is the highest in the world, especially in the northwestern part of the country, which includes the Qinghai province $(2,3)$. Han nationality constitutes the majority population, while the Tibet and Hui nationalities are considered minorities. The incidence of GC in the Tibet and Hui populations is higher than that in the Han nationality. However, the study of the Tibet and Hui nationalities is not as advanced due to fewer individuals and poorer economic conditions (4).

Previous studies demonstrated that environmental factors (5), bacterial infection (Helicobacter pylori, H. pylori) (6) and genetic factors (7) are important in GC development. Although the strongest known risk factor for non-cardia GC is $H$. pylori infection and there is a high rate of $H$. pylori infection in Eastern Asians (8,9), only a small proportion of $H$. pylori-infected individuals is likely to develop neoplasia. This is probably due to gastric carcinogenesis depending on specific combinations of bacterial strains, environmental factors and host genetic susceptibility factors $(10,11)$.

Findings of recent studies have detected the associations between genetic polymorphisms and risk of GC $(12,13)$. In 2008, the Study Group of the Millennium Genome Project for Cancer found an association between the rs2294008 single nucleotide polymorphism (SNP) in the prostate stem cell antigen gene (PSCA) and the risk of GC in Japanese and Korean populations (14). The association between GC and rs2294008 has also been identified in Chinese Han and Caucasian populations $(15,16)$.

Absence of concomitant $H$. pylori infection may be a factor confounding the contribution of gene variants to disease $(17,18)$. Moreover, certain gene polymorphisms have been confirmed to differentially affect GC development among various populations (19). Therefore, a case-control study was conducted to investigate the potential etiologic role of rs 2294008 polymorphism in $H$. pylori-negative patients from the Tibet, Hui and Han nationalities in the Qinghai region of China. 


\section{Materials and methods}

Study subjects. Consecutive healthy controls and patients with $H$. pylori-negative, non-cardia cancer were enrolled. The Tibet, Hui and Han nationalities from the Qinghai Province of China were selected for this study. This case-control study was approved by the institutional review board of Qinghai University. Healthy controls included 286 Tibet, 315 Hui and 350 Han individuals enrolled from the Hainan Tibet Nationality Autonomous Prefecture, Minhe Hui Nationality Autonomous County and Xining city in the Qinghai province, respectively. Between January, 2009 and May, 2012, 219, 233 and 265 Tibet, Hui and Han individuals, respectively, suffering from GC were enrolled in this study from the Affiliated Hospital of Qinghai University. Recruited healthy controls were from families that had a history of longevity in that locality, did not marry other nationalities for at least three generations and did not have blood relations with each other. Age, gender and smoking status of healthy controls were matched to patients and are shown in Table I. The GC cases were histopathologically diagnosed and the exclusion criteria of GC cases included having a history of any cancer or any metastasized cancer (carcinomas were not originally from stomach) and having undergone radiotherapy or chemotherapy. Subjects with a family history of any cancer were also excluded. The patients were histologically confirmed as having non-cardia GC. Subjects who consented to participate in the study and donate blood samples were included in this study. Each subject was personally (face-to-face) interviewed by trained interviewers, using a pretested questionnaire to obtain information on demographic data and smoking habits. The presence of $H$. pylori infection in the sera of patients and controls was measured with an enzyme-linked immunosorbent assay (anti- $H$. pylori enzyme immunoassay; Huamei Biotech Inc., Wuhan, China).

Genotype analyses. Genomic DNA was isolated from $5 \mathrm{ml}$ of venous blood by the conventional proteinase $\mathrm{K}$ digestion and phenol/chloroform extraction method. Polymorphism was analyzed by PCR-based denaturing high-performance liquid chromatography (DHPLC). Primers were synthesized at the Beijing Aoke Biological Engineering Technology and Services (Beijing, China), and are shown together with PCR conditions, PCR annealing temperatures and DHPLC detection methods in Table II. PCR was performed with a $25 \mathrm{ml}$ reaction mixture containing $100 \mathrm{ng}$ of genomic DNA, $1.0 \mathrm{mM}$ of primer, $0.2 \mathrm{mM}$ of dNTP, $2.0 \mathrm{mM}$ of $\mathrm{MgCl}_{2}$ and 1.0 Taq units DNA polymerase in $1 \mathrm{X}$ reaction buffer (Promega, Madison, WI, USA). DHPLC analysis was performed on a Transgenomic $\mathrm{WAVE}^{\circledR}$ System. The detailed genotyping process has been previously described (20). The PCR products were applied to the DHPLC column at an optimal oven temperature and eluted with a linear acetonitrile gradient at a flow rate of $0.9 \mathrm{ml} / \mathrm{min}$. The genotypes identified by DHPLC analysis were confirmed by DNA sequencing with the ABI Prism 377 DNA Sequencer.

Helicobacter pylori antibody assays. Enzyme-linked immunosorbent assay for the detection of H. pylori was performed as per the manufacturer's instructions. Following termination of the enzyme reaction, absorbance at $630 \mathrm{~nm}$ was measured. Absorbance ratios (sample/negative control) $\geq 2$.1 were considered positive while ratios of $<2.1$ were considered negative.

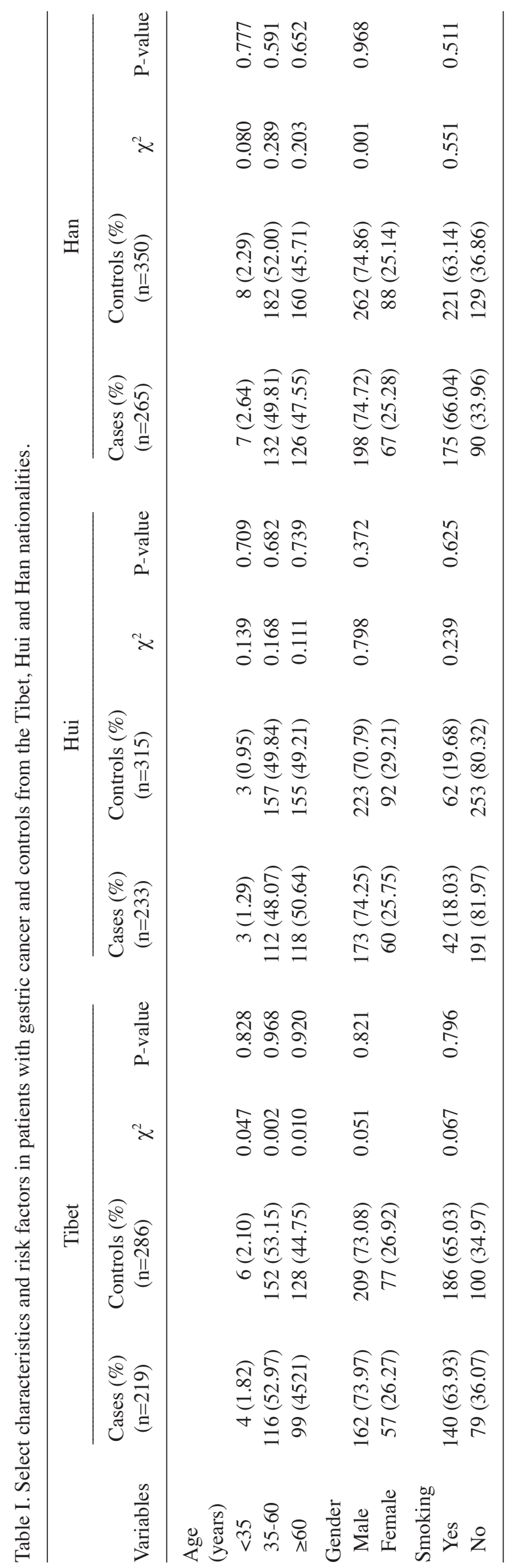


Table II. Primer sequences, PCR and DHPLC conditions for the detection of gene polymorphisms.

\begin{tabular}{lcccc}
\hline Gene & Primer sequence & $\begin{array}{c}\text { PCR annealing } \\
\text { temperature }\left({ }^{\circ} \mathrm{C}\right)\end{array}$ & $\begin{array}{c}\text { PCR product size } \\
(\mathrm{bp})\end{array}$ & $\begin{array}{c}\text { DHPLC } \\
\text { application type }\end{array}$ \\
\hline PSCA & $\begin{array}{l}\text { F: AGTCACCTGAGGCCCTCTC } \\
\text { R: CTGCAGCCTTTGCTGATGACG }\end{array}$ & 59 & 241 & Mutation \\
\end{tabular}

PCR, polymerase chain reaction; DHPLC, denaturing high-performance liquid chromatography.

Statistical analysis. Data were analyzed using SPSS software version 17.0 (SPSS, Chicago, IL, USA). The significance of the difference in the distribution of the polymorphisms among different groups was calculated using the $\chi^{2}$ test. The allelic distributions were examined for deviations from their corresponding Hardy-Weinberg equilibrium. Multivariate logistic regression was used to obtain odds ratios (ORs) and 95\% confidence intervals (CIs), adjusting for age, gender and smoking status. $\mathrm{P}<0.05$ (two-tailed) was considered to indicate a statistically significant difference.

\section{Results}

Clinical characteristics. The study population comprised 286 healthy controls and 219 GC patients from the Tibet nationality, 315 healthy controls and $233 \mathrm{GC}$ patients from the Hui nationality and 350 healthy controls and 265 GC patients from the Han nationality. Age, gender and smoking status of the GC patients and control subjects are shown in Table I. The healthy controls and GC patients were consecutive H.pylori-negative. No statistically significant differences were identified between the cases and controls among age, gender and smoking status in each nationality group. The genotype frequencies of rs2294008 in the controls in each nationality group were in agreement with the Hardy-Weinberg equilibrium ( $\mathrm{P}>0.05$ for all).

PSCA rs2294008 gene polymorphism and association with $G C$. The frequencies of genotypes rs2294008 gene polymorphism among the Tibet, Hui and Han nationalities are summarized in Table III. In the Tibet nationality group, the rs2294008 CT genotype was significantly more frequent in GC patients $(47.03 \%)$ compared with controls $(39.51 \%)\left(\chi^{2}=4.75\right.$ $\mathrm{P}=0.030$ ). The risk of developing $\mathrm{GC}$ with this genotype was significantly increased (adjusted $\mathrm{OR}=1.51$; 95\% CI, 1.04-2.19; $\mathrm{P}=0.030$ ). The rs2294008 TT genotype also occurred more frequently in GC patients $(10.50 \%)$ compared with controls $(6.64 \%)\left(\chi^{2}=4.37, \mathrm{P}=0.039\right)$. The risk of developing $\mathrm{GC}$ with this genotype was also significantly increased (adjusted $\mathrm{OR}=2.01 ; 95 \% \mathrm{CI}, 1.04-3.88 ; \mathrm{P}=0.030$ ).

Unlike the results obtained from individuals belonging to the Tibet populations, in the Hui nationalitiy group, there were no differences in the frequencies of the rs2294008 CT genotypes between GC patients and controls $\left(\chi^{2}=2.82, \mathrm{P}=0.093\right)$. However, the rs2294008 TT genotype was identified more frequently in GC patients $(21.03 \%)$ compared with controls $(13.02 \%)\left(\chi^{2}=8.88, P=0.003\right)$. The risk of developing GC with this genotype was significantly increased (adjusted $\mathrm{OR}=2.14$; 95\% CI, 1.29-3.55; $\mathrm{P}=0.003$ ).
Results obtained from the Tibet region showed two genotype sites were associated with GC in the Han nationality. For the rs2294008 CT genotype, there was a significant difference between GC patients (47.92\%) and controls $(40.86 \%)\left(\chi^{2}=4.61\right.$, $\mathrm{P}=0.025)$. The risk of developing GC with rs2294008 CT genotypes was significantly increased (adjusted $\mathrm{OR}=1.47$; 95\% CI, 1.05-2.06; $\mathrm{P}=0.025$ ). In addition, for the rs 2294008 TT genotype, there was a statistically significant difference in the TT genotype distribution between GC (10.57\%) and controls $(7.14 \%)\left(\chi^{2}=8.70, \mathrm{P}=0.040\right)$. The risk of developing GC with rs2294008 TT genotype was significantly increased (adjusted $\mathrm{OR}=1.85,3.53$; 95\% CI, 1.03-3.34; $\mathrm{P}=0.004$ ).

Association of PSCA rs2294008 with clinicopathological features. Stratified analyses were performed according to histopathology (Lauren's classification) with adjustment for age, gender and smoking status. The prevalence of rs2294008 polymorphism in different GC subtypes was analyzed. In this study, gastric carcinomas were of intestinal histotype in $153(69.86 \%), 156(66.95 \%)$ and 188 patients (70.94\%) and of diffuse histotype or mixed-type GC in 66 patients $(30.14 \%)$, $77(33.05 \%)$ and 77 patients $(29.06 \%)$ from the Tibet, Hui and Han nationalities, respectively. The frequencies of rs2294008 genotypes among intestinal-type and diffuse or mixed-type GC from the three populations are recorded in Table IV.

Similar results were observed in both the Tibet and Han nationality groups. For individuals belonging to the Tibet nationality group, the rs2294008 CT and TT genotypes was only associated with diffuse $\mathrm{GC}(\mathrm{P}=0.025$ and 0.038 , respectively) with adjusted OR of 1.93 (95\% CI, 1.09-3.44) and 2.69 (95\% CI, 1.06-6.84). However, the rs2294008 CT and TT genotypes were not associated with intestinal-type $\mathrm{GC}(\mathrm{P}=0.142$ and 0.129 , respectively; adjusted $\mathrm{OR}=1.36$; 95\% CI, 0.90-2.06; 1.76, 0.85-3.69, respectively) (Table IV). Additionally, for individuals belonging to the Han nationality group, the rs2294008 CT and TT genotypes were also only associated with diffuse GC ( $\mathrm{P}=0.045$ and 0.011 , respectively) with adjusted $\mathrm{OR}$ of 1.73 (95\% CI, 1.01-2.95) and 2.86 (95\% CI 1.27-6.46). However, the rs2294008 CT and TT genotypes were not associated with intestina-type $\mathrm{GC}(\mathrm{P}=0.088$ and 0.228 , respectively; adjusted $\mathrm{OR}=1.38 ; 95 \%$ CI, 0.95-2.00; 1.51, 0.77-2.95, respectively).

Unlike the results obtained from individuals belonging to the Tibet and Han populations, the rs2294008 TT genotype in the Hui nationalitiy group, was associated with both intestinal and diffuse types of $\mathrm{GC}(\mathrm{P}=0.012$ and 0.023 , respectively) with adjusted ORs of 2.10 and 2.21 (95\% CI, 1.17-3.75 and 1.12-4.38, respectively). Nevertheless, the rs2294008 CT genotype was only associated with intestinal-type GC $(\mathrm{P}=0.034)$ with an 
Tables III. Genotype distributions of rs2294008 polymorphism among gastric cancer cases and controls from the Tibet, Hui and Han nationalities.

\begin{tabular}{cccc}
\hline Genotype & Cases, n $(\%)$ & Controls, $n(\%)$ & OR $(95 \% \text { CI })^{\mathrm{a}}$ \\
\hline Tibet & 219 & 286 & 1 \\
CC & $93(42.47)$ & $154(53.85)$ & $1.51(1.04-2.19)$ \\
CT & $103(47.03)$ & $113(39.51)$ & $2.01(1.04-3.88)$ \\
TT & $23(10.50)$ & $19(6.64)$ & 1 \\
Hui & 233 & 315 & $1.38(0.95-2.02)$ \\
CC & $72(30.90)$ & $129(40.95)$ & $2.14(1.29-3.55)$ \\
CT & $112(48.07)$ & $145(46.03)$ & 0.039 \\
TT & $49(21.03)$ & $41(13.02)$ & 1 \\
Han & 265 & 350 & $1.47(1.05-2.06)$ \\
CC & $110(41.51)$ & $182(52.00)$ & $1.85(1.03-3.34)$ \\
CT & $127(47.92)$ & $143(40.86)$ & 0.093 \\
TT & $28(10.57)$ & $25(7.14)$ & 003 \\
\hline
\end{tabular}

${ }^{\text {a} A d j u s t e d ~ f o r ~ a g e, ~ g e n d e r ~ a n d ~ s m o k i n g ~ s t a t u s . ~}$

Table IV. Genotype distributions of the rs2294008 polymorphism among different subtypes of gastric cancer from the Tibet, Hui and Han nationalities.

\begin{tabular}{|c|c|c|c|c|c|c|c|}
\hline \multirow[b]{2}{*}{ Genotype } & \multirow[b]{2}{*}{ Controls, n (\%) } & \multicolumn{3}{|c|}{ Intestinal cases } & \multicolumn{3}{|c|}{ Diffuse cases } \\
\hline & & Cases & OR $(95 \% \mathrm{CI})^{\mathrm{a}}$ & P-value & Cases & OR $(95 \% \mathrm{CI})^{\mathrm{a}}$ & P-value \\
\hline \multicolumn{8}{|l|}{ Tibet } \\
\hline $\mathrm{CC}$ & $154(53.85)$ & $69(45.10)$ & 1 & & $24(36.36)$ & 1 & \\
\hline $\mathrm{CT}$ & $113(39.51)$ & $69(45.10)$ & $1.36(0.90-2.06)$ & 0.142 & $34(51.52)$ & $1.93(1.09-3.44)$ & 0.025 \\
\hline $\mathrm{TT}$ & $19(6.64)$ & $15(9.80)$ & $1.76(0.85-3.69)$ & 0.129 & $8(12.12)$ & $2.69(1.06-6.84)$ & 0.038 \\
\hline \multicolumn{8}{|l|}{ Hui } \\
\hline $\mathrm{CC}$ & $129(40.95)$ & $45(28.85)$ & 1 & & $27(35.06)$ & 1 & \\
\hline $\mathrm{CT}$ & $145(46.03)$ & $81(51.92)$ & $1.60(1.04-2.47)$ & 0.034 & $31(40.26)$ & $1.02(0.58-1.18)$ & 0.941 \\
\hline TT & $41(13.02)$ & $30(19.23)$ & $2.10(1.17-375)$ & 0.012 & $19(24.68)$ & $2.21(1.12-4.38)$ & 0.023 \\
\hline \multicolumn{8}{|l|}{ Han } \\
\hline $\mathrm{CC}$ & $182(52.00)$ & $82(43.62)$ & 1 & 0.005 & $28(36.36)$ & $1.79(0.85-3.77)$ & 0.126 \\
\hline $\mathrm{CT}$ & $143(40.86)$ & 89 (47.34) & $1.38(0.95-2.00)$ & 0.088 & $38(49.35)$ & $1.73(1.01-2.95)$ & 0.045 \\
\hline TT & $25(7.14)$ & $17(9.04)$ & $1.51(0.77-2.95)$ & 0.228 & $11(14.29)$ & $2.86(1.27-6.46)$ & 0.011 \\
\hline
\end{tabular}

${ }^{a}$ Adjusted for age, gender and smoking status.

adjusted OR of 1.60 (95\% CI, 1.04-2.47) and was not associated with diffuse $\mathrm{GC}(\mathrm{P}=0.941$; adjusted $\mathrm{OR}=1.02$; 95\% CI, 0.58-1.8). No other significant associations were found when GC patients were classified according to age, gender, or smoking status.

\section{Discussion}

To the best of our knowledge, this is the first study examining the associations between rs2294008 polymorphism and GC risk among several nationalities in one region at the same time and also the first study to investigate the association between rs2294008 polymorphism and GC in a Hui population. In this case-control study, we investigated the association between rs2294008 polymorphism and $H$. pylori-negative non-cardia
GC among three nationalities, including Tibet, Hui and Han nationalities, in the Qinghai area of China. We found that rs2294008 CT and TT were associated with a significantly increased risk of GC in both the Tibet and Han nationalities, while the rs2294008 TT genotype was associated with a significantly increased risk of GC in the Hui nationalitiy. Additionally, we found that rs2294008 CT and TT were associated with a significantly increased risk of diffuse GC only in the Tibet and Han populations, whereas the rs2294008 TT genotype was associated with intestinal and diffuse GC in the Hui population, with the rs2294008 CT genotype being associated only with intestinal-type gastric in this population. These findings indicate that rs2294008 may contribute to the etiology of gastric carcinogenesis and rs2294008 may differ- 
entially contribute to GC among various nationalities in one region and its roles are independent from $H$. pylori infection.

PSCA maps on chromosome 8q24.2 (21), comprising 3 exons and 2 introns. PSCA is a member of the LY-6/Thy-1 family of glycosylphosphatidylinosi-tol-anchored cell surface proteins and is a human cancer marker closely related to stem cell antigens $(21,22)$. PSCA was overexpressed in prostate (23) and pancreatic cancer, (24), however, its expression decreased in head and neck squamous cell carcinoma (25), as well as urothelium, kidney, esophageal, bladder and stomach cancer $(26,27,14)$. Previous studies have shown that PSCA may be involved in signal transduction and cell growth regulation in various systems $(28,29)$. In 2008, a two-stage genome-wide association study of GC in Japanese and Korean populations, identified a SNP 2294008, in exon 1 of PSCA, associated with susceptibility to diffuse GC (14). The authors noted that the risk allele ' $\mathrm{T}$ ' of rs2294008 reduced transcriptional activity of an upstream fragment of the gene. Recently, this allele has been identified to be associated with susceptibility to GC risk in Chinese Han and Caucasian populations $(15,16)$. At least two meta-analyses on associations between PSCA polymorphisms and GC have been reported. Findings of meta-analysis examining nine case-control studies comprising 10,746 cases and 9,158 controls demonstrated that the PSCA rs2294008 C-T polymorphism exhibited a significantly increased risk of $\mathrm{GC}$ in the genetic models (TT/TC vs. CC: $\mathrm{OR}=1.61 ; 95 \% \mathrm{CI}$, 1.35-1.91; TT vs. TC/CC: $\mathrm{OR}=1.33$; 95\% CI, 1.24-1.42) and that this polymorphism may contribute to susceptibility to GC, particularly in non-cardia or diffuse GC. Furthermore, in the stratified analysis ethnicity of rs2294008, an increased GC risk was found in both Asians (TT vs. TC/CC: $\mathrm{OR}=1.31$; 95\% CI, 1.22-1.42) and Europeans (TT/TC vs. CC: $\mathrm{OR}=1.42$; 95\% CI, 1.18-1.71) (30). Another meta-analysis that included eight case-control studies in seven articles comprising 9,738 cases of GC and 7,054 controls indicated that the T allele of rs2294008C $>\mathrm{T}$ was significantly associated with increased GC risk [rs2294008C >T: OR $(95 \%$ CI $)=1.31(1.22-1.42)$, Pz-test $<0.001]$. Results of the subgroup analyses indicated that $\mathrm{T}$ allele of rs2294008C $>\mathrm{T}$ was associated with increased risk of both intestinal and diffuse GC, GC for Eastern Asian (including Chinese, Japanese, Koreans, PCC and HCC/PHCC), cardia and non-cardia GC and GC for males and females (31).

Our study suggests that carriers of the PSCA rs2294008 CT and TT genotypes had increased risks of GC in the Tibet and Han nationalities in the Qinghai area of China. These results are consistent with most studies on Chinese Han and Tibet, as well as Japanese, Korean and Caucasian populations, were rs2294008 CT and TT genotypes were found to be associated with an increased risk of GC (16,32-35). However, only rs2294008 TT genotypes had an increased risk of GC in the Hui nationality in contrast to the Tibet and Han nationalities. Associations between rs2294008 and GC risk among the Tibet, Han and Hui nationalities were consistent regardless of age, gender or smoking status. The patients and controls enrolled in this study were $H$. pylori-negative and matched with regards to age, gender and smoking status. Therefore, our results suggest that rs2294008 was an independent risk factor of GC, which is in concordance with previous studies $(16,34)$.

Of note, when GC cases were subclassified according to their histological type (intestinal, diffuse or mixed) the asso- ciation between rs2294008 and GC risk among the Tibet, Hui and Han nationalities was not identical. rs2294008 CT and TT genotypes were associated with diffuse but not intestinal-type GC in the Tibet and Han nationality groups. These findings are in agreement with those previously reported, including studies from Japanese and Caucasian populations $(14,16)$. Nevertheless, the rs2294008 TT genotype was associated with both intestinal and diffuse types of GC, while the rs2294008 CT genotype was only associated with intestinal-type GC in the Hui nationalitiy group. A similar finding was observed in two Chinese Han populations $(32,36)$.

Descrepancies in the association between rs2294008 genotypes and GC among the Tibet, Hui and Han nationalities are associated with different inherited gene backgrounds. Geographically restricted positive selection due to distinct environmental pressures often results in large allele frequency differences between populations. Studies have shown that differential genetic/environmental interactions in different ethnic groups resulted in altered gene expression and altered effects on cell growth and the development of GC (19,37). The gene distribution of rs2294008 among the Tibet, Hui and Han nationalities in Qinghai was not identical. Our data might reflect the effect of past selective pressures on genotypes of Tibet, Hui and Han nationalities over a long period of time. The rs2294008 CT and TT genotypes were similar in the Tibet (39.51\%, 6.64, respectively) and Han (40.86\%, 7.14, respectively) populations, but were significantly lower than those of the Hui population (46.03\%, 13.02, respectively). The Han nationality constitutes the majority population, while Tibetans are a minority in the Qinghai area in China, with both groups having resided in a high-altitude area for a long period of time, thus their physical and physiological functions have altered to adapt to hypoxic environments (38). A recent study has identified that advantageous gene variations are associated with human adaptation at high altitudes (39), thus, genetic susceptibility of the Tibet and Han populations may yield different results from Han populations only. The Hui nationality, which migrated from Central Asia,Persia and the Arab world, is also a minority in the Qinghai area in China. A study analyzed $\mathrm{M}^{*}, \mathrm{~N}^{*}$ and $\mathrm{R}^{*}$ mtDNAs and found that the western Eurasian specific haplogroup frequency in the Hui population was $6.7 \%$ but no western Eurasian type was found in Han Chinese samples from the same region (40). The Hui nationality has its own gene characteristics. Both the Tibet and Hui nationalities carry out endogamy and tend to be ethnically homogeneous. Therefore, the Tibet, Hui and Han nationalities in the Qinghai area in China likely have different gene traits leading to different associations between PSCA rs2294008 polymorphism and GC risk.

The present study was limited in patient and control size. Additionally, factors including education or consumption of alcohol, fresh fruits or vegetables in the controls were not considered, while varying eating habits among patients and controls were not investigated. In general, the Tibet nationality diet contains more meat and lacks certain nutrients, may potentially increasing GC risk. The Hui nationality observes Ramadan and eats refrigerated foods, potentially causing gastric mucosa pathological changes.

In conclusion, the present study has shown different associations of the rs2294008 polymorphism and GC risk among the Tibet, Hui and Han nationalities in the Qinghai area of 
China. rs2294008 CT and TT genotypes were associated with diffuse GC in the Tibet and Han nationalities. Although the rs2294008 TT genotype was associated with both intestinal and diffuse types of GC, the rs2294008 CT genotype was only associated with intestinal-type GC in the Hui nationalitiy group. These results demonstrate that rs 2294008 may differentially contribute to GC among different nationalities in a particular region and its roles are independent of $H$. pylori infection.

\section{Acknowledgements}

This study was supported in part by grants from the National Natural Science Foundation of China (no. 30860259), and by Youth Scientific Research Foundation of the Affiliated Hospital of Qinghai Uuniversity (no. ASRF-2009-09).

\section{References}

1. Parkin DM, Bray F, Ferlay J and Pisani P: Global cancer statistics, 2002. CA Cancer J Clin 55: 74-108, 2005.

2. Sun XD, Mu R, Zhou YS, et al: Investigation and analysis on mortality of gastric cancer in China between 1990-1992. Chin J Oncol 24: 4-8, 2002 (In Chinese).

3. Yang L, Parkin DM, Ferlay J, Li L and Chen Y: Estimates of cancer incidence in China for 2000 and projections for 2005. Cancer Epidemiol Biomarkers Prev 14: 243-250, 2005.

4. Zhao JD, Sheng GS, Cao CZ, et al: Analysis on the morbidity feature among Tibet, Hui and Han nationalities with gastric cancer in Qinghai area. Chin J Intern Med 48: 955-956, 2009 (In Chinese).

5. Moy KA, Fan Y, Wang R, Gao YT, Yu MC and Yuan JM: Alcohol and tobacco use in relation to gastric cancer: a prospective study of men in Shanghai, China. Cancer Epidemiol Biomarkers Prev 19: 2287-2297, 2010.

6. Konturek PC, Konturek SJ and Brzozowski T: Helicobacter pylori infection in gastric cancerogenesis. J Physiol Pharmacol 60: 3-21, 2009.

7. Shanks AM and El-Omar EM: Helicobacter pylori infection, host genetics and gastric cancer. J Dig Dis 10: 157-164, 2009.

8. Houghton J and Wang TC: Helicobacter pylori and gastric cancer: a new paradigm for inflammation-associated epithelial cancers. Gastroenterology 128: 1567-1578, 2008.

9. Polk DB and Peek RM Jr: Helicobacter pylori: gastric cancer and beyond. Nat Rev Cancer 10: 403-414, 2010.10.

10. Gonzalez CA, Pera G, Agudo A, Palli D, et al: Smoking and the risk of gastric cancer in the European Prospective Investigation Into Cancer and Nutrition (EPIC). Int J Cancer 107: 629-634, 2003.

11. Gonzalez CA, Sala N and Capella G: Genetic susceptibility and gastric cancer risk. Int J Cancer 100: 249-260, 2002.

12. Burada F, Angelescu C, Mitrut P, et al: Interleukin-4 receptor $-3223 \mathrm{~T} \rightarrow \mathrm{C}$ polymorphism is associated with increased gastric adenocarcinoma risk. Can J Gastroenterol 26: 532-536, 2012.

13. Zhang Y, Wang ZT and Zhong J: Meta-analysis demonstrates that the NAD $(\mathrm{P}) \mathrm{H}$ : quinone oxidoreductase 1 (NQO1) gene 609 $\mathrm{C}>\mathrm{T}$ polymorphism is associated with increased gastric cancer risk in Asians. Genet Mol Res 11: 2328-2337, 2012.

14. Sakamoto H, Yoshimura K, Saeki N, et al: Genetic variation in PSCA is associated with susceptibility to diffuse-type gastric cancer. Nat Genet 40: 730-740, 2008.

15. Wu C, Wang G, Yang M, et al: Two genetic variants in prostate stem cell antigen and gastric cancer susceptibility in a Chinese population. Mol Carcinog 48: 1131-1138, 2009.

16. Lochhead P, Frank B, Hold GL, et al: Genetic variation in the prostate stem cell antigen gene and upper gastrointestinal cancer in white individuals. Gastroenterology 140: 435-441, 2011.

17. Koivurova OP, Karhukorpi JM, Joensuu ET, et al: IL-1 RN $2 / 2$ genotype and simultaneous carriage of genotypes IL-1 RN 2/2 and IL-1beta-511 T/T associated with oesophagitis in Helicobacter pylori-negative patients. Scand J Gastroenterol 38: 1217-1222, 2003

18. Tahara E: Genetic pathways of two types of gastric cancer. IARC Sci Publ 157: 327-349, 2004.
19. Won HH, Kim JW, Kim MJ, Kim S, Park JH and Lee KA: Interleukin 10 polymorphisms differentially influence the risk of gastric cancer in East Asians and Caucasians. Cytokine 51: 73-77, 2010

20. Lu W, Pan K, Zhang L, Lin D, Miao X and You W: Genetic polymorphisms of interleukin (IL)-1B, IL-1RN, IL-8, IL-10 and tumor necrosis factor a and risk of gastric cancer in a Chinese population. Carcinogenesis 26: 631-636, 2005.

21. Reiter RE, Gu Z, Watabe T, et al: Prostate stem cell antigen: a cellsurface marker overexpressed in prostatecancer. Proc Natl Acad Sci USA 95: 1735-1740, 1998.

22. Gumley TP, McKenzie IF and Sandrin MS: Tissue expression, structure and function of the murine Ly- 6 family of molecules. Immunol Cell Biol 73: 277-296, 1995.

23. Gu Z, Thomas G, Yamashiro J, et al: Prostate stem cellantigen (PSCA) expression increases with high gleason score, advanced stage and bone metastasis in prostate cancer. Oncogene 19: 1288-1296, 2000.

24. Argani P, Rosty C, Reiter, RE, et al: Discovery of new markers of cancer through serial analysis of gene expression: prostate stem cell antigen is overexpressed in pancreatic adenocarcinoma. Cancer Res 61: 4320-4324, 2001.

25. de Nooij-van Dalen AG, van Dongen GA, Smeets SJ, Nieuwenhuis EJ, Stigter-van Walsum M, Snow GB and Brakenhoff RH: Chracterization of the human LY-6 antigens, the newly annotated member Ly-6K included, as molecular markers for head-and-neck squamous cell carcinoma. Int J Cancer 103: 768-774, 2003

26. Bahrenberg G, Brauer A, Joos HG and Jakse G: Reduced expression of PSCA, a membe of the LY- 6 family of cell surface antigens, in bladder, esophagus and stomach tumors. Biochem Biophys Res Commun 275: 783-788, 2000.

27. Wang S, Tang J, Wang M, Yuan L and Zhang Z: Genetic variation in PSCA and bladder cancer susceptibility in a Chinese population. Carcinogenesis 31: 621-624, 2010.

28. Saffran DC, Raitano AB, Hubert RS, Witte ON, Reiter RE and Jakobovits A: Anti-PSCA mAbs inhibit tumor growth and metastasis formation and prolong the survival of mice bearing human prostate cancer xenografts. Proc NatlAcad Sci USA 98: 2658-2663, 2001

29. Gu Z, Yamashiro J, Kono E and Reiter RE: Anti-prostate stem cell antigen monoclonal antibody $1 \mathrm{G} 8$ induces cell death in vitro and inhibits tumor growth in vivo via a Fc-independent mechanism. Cancer Res 65: 9495-9500, 2005.

30. Shi D, Wang S, Gu D, et al: The PSCA polymorphisms derived from genome-wide association study are associated with risk of gastric cancer: a meta-analysis. J Cancer Res Clin Oncol 138: 1339-1345, 2012.

31. Qiao L and Feng Y: Genetic variations of prostate stem cell antigen (PSCA) contribute to the risk of gastric cancer for Eastern Asians: a meta-analysis based on 16792 individuals. Gene 493: 83-91, 2012.

32. Zeng Z, Wu X, Chen F, et al: Polymorphisms in prostate stem cell antigen gene rs2294008 increase gastric cancer risk in Chinese. Mol Carcinog 50: 353-358, 2011

33. Ou J, Li K, Ren H, Bai H, Zeng D and Zhang C: Association and haplotype analysis of prostate stem cell antigen with gastric cancer in Tibetans. DNA Cell Biol 29: 319-323, 2010.

34. Matsuo K, Tajima K, Suzuki T, et al: Association of prostate stem cell antigen gene polymorphisms with the risk of stomach cancer in Japanese. Int J Cancer 125: 1961-1964, 2009.

35. Song HR, Kim HN, Piao JM, et al: Association of a common genetic variant in prostate stem-cell antigen with gastric cancer susceptibility in a Korean population. Mol Carcinog 50: 871-875, 2011.

36. Lu Y, Chen J, Ding Y, et al: Genetic variation of PSCA gene is associated with the risk of both diffuse- and intestinal-type gastric cancer in a Chinese population. Int J Cancer 127: 2183-2189, 2010

37. Gao L, Nieters A and Brenner H: Meta-analysis: tumour invasion-related genetic polymorphisms and gastric cancer susceptibility. Aliment Pharmacol Ther 28: 565-573, 2008.

38. Wu T and Kayser B: High altitude adaptation in Tibetans. High Alt Med Bio 7: 193-208, 2006.

39. Scheinfeldt LB and Tishkoff SA: Living the high life: high-altitude adaptation. Genome Biol 11: 133, 2010

40. Yao YG, Kong QP, Wang CY, Zhu CL and Zhang YP: Different matrilineal contributions to genetic structure of ethnic groups in the silk road region in China. Mol Biol Evol 21: 2265-2280, 2004. 